\title{
The all-clear signal for rare heart arrhythmias
}

$\mathrm{D}$ iscovering a gene for a rare but often fatal arrhythmia has allowed doctors in Newfoundland and Labrador to prescribe a treatment before any symptoms arise and physicians in northern British Columbia to differentiate symptoms associated with a bad lifestyle from a genetic predisposition for another heart condition.

But has that affected the practice of coronary medicine within the broader Canadian population?

To answer that, consider the case of Grace Verbeek, who finished seventh in the semifinals of the 800-metre competition while representing Canada at the 1984 Summer Olympics. In 2007, when she was 48 , Verbeek recalls arriving at a track facility in Ottawa, Ontario, where she coached. Then her memory runs dry.

She now characterizes it as a day on which "all my little angels lined-up." A coaching colleague noticed her acting strangely and summoned several people to administer cardiopulmonary resuscitation. A cardiologist who was at the facility watching his son play soccer surmised that Verbeek was in cardiac arrest and contacted paramedics.

So almost by chance Verbeek survived. The following day, a battery of tests at the University of Ottawa Heart Institute $(\mathrm{OHI})$ revealed nothing wrong with her heart. So genetic tests were conducted on Verbeek and relatives in Holland.

The tests came back with a genetic fingerprint which predisposes carriers to arrhythmogenic right ventricular cardiomyopathy (ARVC).

Unlike Newfoundlanders or members of the Gitxsan First Nation, the gene had left no discernible mark in Verbeek family records or its oral history. "My mother has done the family tree and has been going through family history for years and there is no record of people suddenly keeling over," she says.

Verbeek now takes beta blockers, has had a defibrillator implanted and has adjusted her exercise regimen to

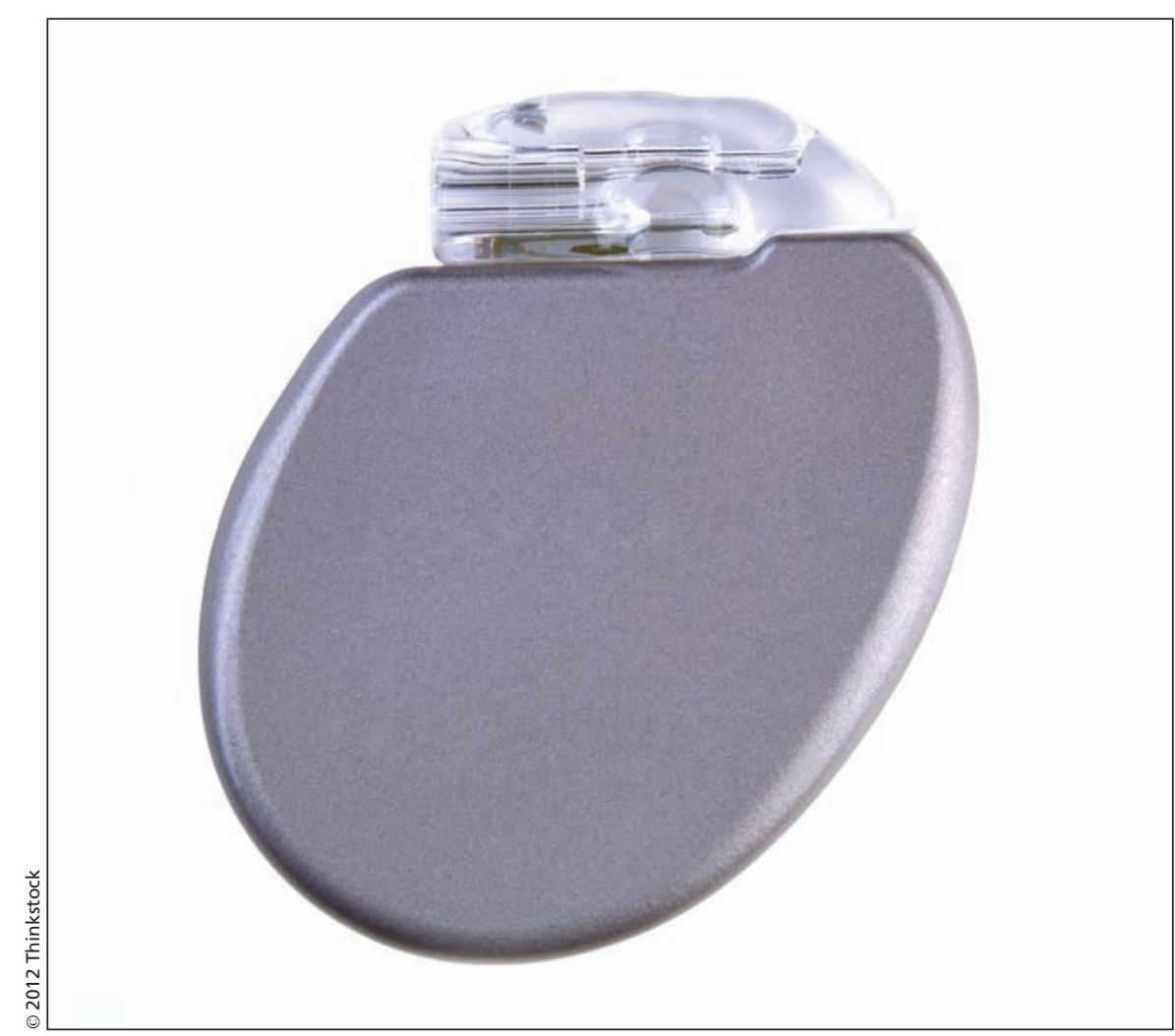

Among therapeutic preventive measures for people with rare heart arrhythmias is the insertion of implantable defibrillators.

avoid sudden spurts in heart rhythm. Other family members who have been shown to be carriers are either being treated or are being closely watched. More distant relatives in Holland have been advised to be tested.

Such cases have helped to provide "much greater clarity" to clinicians "in circumstances where we have good correlation between mutations and a clinical syndrome," says Dr. Robert Gow, a pediatric cardiologist at the Children's Hospital of Eastern Ontario in Ottawa.

But the long-term effect on carriers may be both beneficial and problematic.

"We know that the penetrance in a family is not $100 \%$," says Dr. Michael Gollob, a cardiologist at OHI. "You can carry the bad gene, but you can look perfectly normal your whole life. But your children may not look perfectly normal."
Early identification of a carrier, in some instances, has allowed clinicians to prescribe therapeutic preventive measures, such as medications or defibrillators.

As importantly, argues Dr. Robert Roberts, president, CEO and chief scientific officer of $\mathrm{OHI}$, and one of the original researchers who hunted for the Newfoundland ARVC gene, the findings of a genetic test can give some people an "all-clear" signal by identifying that they aren't carriers.

That's profound, he argues. "If children carry a gene which has been associated with the possibility of a disease or carry an unknown variation for that disease typically they will be followed by echocardiograms not just for every three to five years but probably for the rest of their lives. However, if you do genetic testing and find that half don't have the gene you will avoid the emo- 
tional trauma of a life-long testing, something which is both cost effective and certainly emotionally relieving."

Is it valid, therefore, to conclude that the relative and absolute successes of heart genetics in diagnosing and treating arrhythmias presages a new clinical future for medicine?

Nobody knows, though researchers are sure more and more genetic information will be made available for doctors to try to fit into the dramatically reconfigured diagnosis and treatment models for rare arrhythmias.

"The thing about the genetic revolution that we are realizing is that it is not one pill fits all, not one test fits all," says Alexandre Stewart, associate professor and research at OHI.

Stewart believes future research will inform physicians about which patients over age 50 are best treated with preventive medications. As well, "if you narrow down who you aren't going to treat, you could save a lot of money."
It might not be the genetic revolution that just a decade ago was predicted as imminent, but it lays a foundation for a bit of genetics-based personalized medicine. - Stephen Strauss, Toronto, Ont.

CMAJ 2012. DOI:10.1503/cmaj.109-4104

Third of a three part series:

Part 1: The rhythms of the Rock (www.cmaj.ca/lookup/doi/10.1503/cmaj.109-4102).

Part 2: The heartbeat of a First Nation (www.cmaj.ca/lookup/doi/10.1503/cmaj.109-4103).

Stephen Strauss' research was made possible in part by a \$20 000 Canadian Institutes of Health Research Journalism Award. 